\title{
Modelling Clamping Force Deflection in Dexel- Based Material Removal Simulations
}

\section{Christian Brecher}

RWTH Aachen University Laboratory for Machine Tools and Production Engineering:

Werkzeugmaschinenlabor der RWTH Aachen

Matthäus Loba ( $\nabla$ m.loba@wzl.rwth-aachen.de)

RWTH Aachen University Laboratory for Machine Tools and Production Engineering:

Werkzeugmaschinenlabor der RWTH Aachen https://orcid.org/0000-0002-5498-1444

\section{Marcel Fey}

RWTH Aachen University Laboratory for Machine Tools and Production Engineering:

Werkzeugmaschinenlabor der RWTH Aachen

\section{Research Article}

Keywords: Clamping Force Deflection, Material Removal Simulation, Quality Prediction

Posted Date: June 1st, 2021

DOl: https://doi.org/10.21203/rs.3.rs-517613/v1

License: (c) (1) This work is licensed under a Creative Commons Attribution 4.0 International License.

Read Full License 


\title{
Modelling Clamping Force Deflection in Dexel-Based Material Removal Simulations
}

\author{
Christian Brecher · Matthäus Loba · Marcel Fey
}

Received: date / Accepted: date

\begin{abstract}
Machining simulations of material removal that predict workpiece quality are a key factor in gaining an understanding of the possible causes of manufacturing defects. Particularly in the case of thin-walled workpieces, as are frequently produced in the aerospace industry, the workpiece stiffness is of utmost importance. Form deviations on the final workpiece can result due to the the process force or the clamping situation. This article presents a method for modelling the deformation due to the clamping force in dexelbased material removal simulations. To prevent distortion of the dexel model, triangulated surface meshes are generated separately for the start and end points of a dexel field by means of a Delaunay triangulation for the final contour. With the help of an FE simulation of the near contour state, the resulting displacements for the corner points of the triangles are determined and then inversely displaced. Subsequently, the new start and end points of the machined dexels are determined through a 2D interpolation. The method is validated for flatness and roundness deviations using two specimen workpieces. It shows that the prediction can be significantly improved, especially for thin-walled components.
\end{abstract}

Keywords Clamping Force Deflection - Material Removal Simulation · Quality Prediction

C. Brecher $\cdot$ M. Loba $\cdot$ M. Fey

RWTH Aachen University

Laboratory for Machine Tools and Production Engineering (WZL)

Tel.: +49-241-80 25415

Fax: +49-241-80 625415

E-mail: m.loba@wzl.rwth-aachen.de

\section{Introduction}

Clamping systems are used in production for positioning and fixing workpieces. This can be done for both production and quality control by means of a friction and/or a form fit. In addition to accessibility to the component, it is important to ensure that the clamping force is large enough to prevent any movement due to external forces, e.g. process forces. At the same time, it must be guaranteed that the deformations occuring as a result of the clamping force do not exceed the permissible tolerances.[1]

In the course of increasing digitalisation, process planning with the help of CAM systems has become an industrial standard. In addition to path planning, they usually include both a material removal simulation and a collision detection based on geometric-kinematic machine models. The clamping situation can also be taken into account. By integrating the control behaviour, production times can also be predicited. All this offers potential for process optimisation even before the beginning of production. [2-4]

While analytical/continuous approaches, such as constructive solid geometry representations (CSG) [5], are mainly used for process planning, e.g. for the simulation of material removal, discrete approaches are preferred for process modelling. Especially the modelling by means of contour lines, dexels and voxels should be mentioned here. [6] Possible areas of application of process modelling are quality-predictive CAM simulations [7] or the monitoring of processes [8-11]. Here, different effects such as thermal and mechanical influences can be mapped [10,12-14]. Mechanical influences can lead to deformations on the tool side as well as on the workpiece side and cause shape deviations on the component. Especially with thin-walled work- 

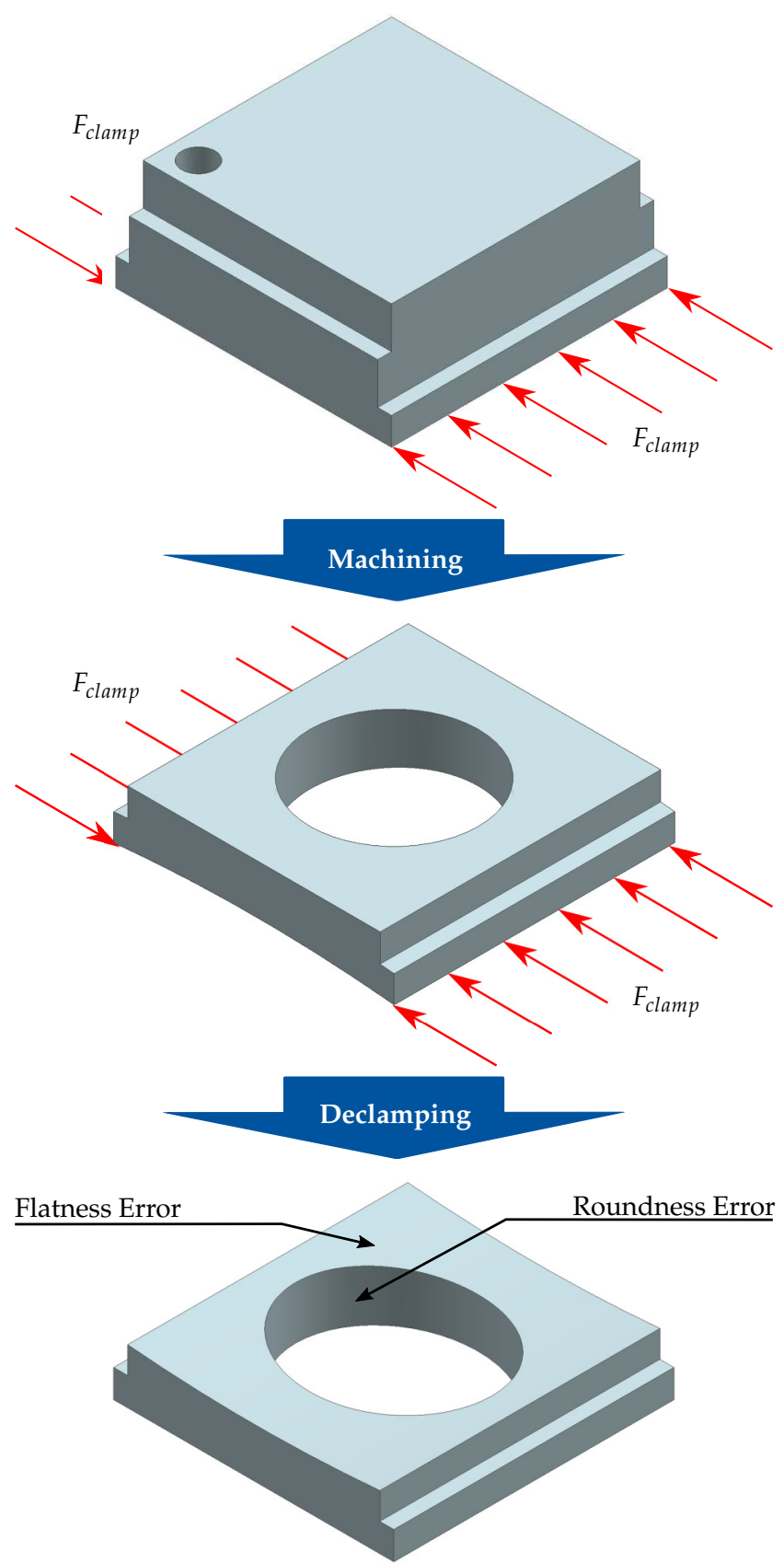

Fig. 1: Clamping Deflection Errors

pieces, such as those found in aerospace, the workpiece stiffness affects on the resulting component quality. Form deviations can occur due to the process force [15] and due to the clamping force [16,17]. The present article presents a method for modeling the deformation due to the clamping force in dexel-based material removal simulations. Since dexels can only be lengthened or shortened and not distorted, a direct threedimensional deformation of the workpiece is not possible. The method presented in this article circumvents this problem by transforming the dexel model into a boundary point cloud (BPC) model and then transforming it back.

\section{Related Work}

Modelling of influences on the accuracy of machining processes as a result of the clamping situation of workpieces is subject of many research papers. In addition to effects arising due to incorrect adjustment of the component, the focus is primarily on work that uses FE simulations to determine the deformation of the part and its resulting stiffness due to the clamping $[1,16,18,19]$. In many cases, iterative methods are used to minimise the clamping force/deformation or to realise a uniform deformation [20,21]. Huang and Yoshi compensate the deformation caused by process heat by specifically modifying the clamping force [22]. More recent work deals with an adjustment of the cutting parameters or the tool path at locations with low stiffness or high deformation of the workpiece [17,23]. In [24], Knape et. al. present a method for modelling the workpiece deformation due to the clamping force in a dexel-based material removal simulation. With the help of an FE simulation, the dexels are initially lengthened/shortened at the beginning of the process and shortened/lengthened at the end of the machining process. In a first step, the prediction accuracy regarding the flatness is improved. In a later work, this methodology is validated for further tolerances [25]. The disadvantage of this method, however, is that it is only suitable for modelling the effect in the near-net-shape state, or for machining operations in which the deformation of the workpiece does not change significantly during the process. This article therefore presents a method making it possible to model the effect of workpiece deformation as a result of the clamping force independently of the raw state of the workpiece.

\section{Principal Modelling Approach}

The present work uses the existing machining simulation from [10]. Machine-internal data is read out parallel to the process from the NC control to determine the material removal. The machine behaviour can be modelled with the help of the available data. In addition, data can be used to execute a process force estimation [26]. Together with background information such as the machine and tool stiffness, the displacement at the tool centre point (TCP) can be determined. In contrast to [24], the simulation is initially executed without taking the clamping situation into account. After 
machining is completed, the Dexel model is converted into a BPC model. Separate point clouds are generated for the start and end points for each Dexel direction. Furthermore, the individual point clouds can be further segmented/clustered. This can be done featureor position-related and is necessary, for example, if a dexel has several start and end points. Possible positionrelated segmentations can be done with manually, defined, equal or geometric interval or also using natural breaks (Jenks) [27,28]. Subsequently, the individual point clouds are meshed by a Delaunay triangulation. The triangulation is done in the respective dexel plane so that a triangular net is created. For the individual corner points of the triangles, the displacements due to the clamping forces are now determined using a scatterd interpolant [29] and the FE simulation. By moving the corner points in the negative displacement direction, the component distortion due to the clamping forces is reproduced. If no further production step follows after declamping, the displaced point clouds can be used directly for quality evaluation, e.g. according to ISO 1101 [30]. If further production steps follow, the point clouds must be transformed back into a Dexel model. By means of a 2D interpolation and the corresponding triangular net, the new start and end points of the processed Dexel are determined. Finally, a Dexel model in a declamped state results that can be used for further processing.

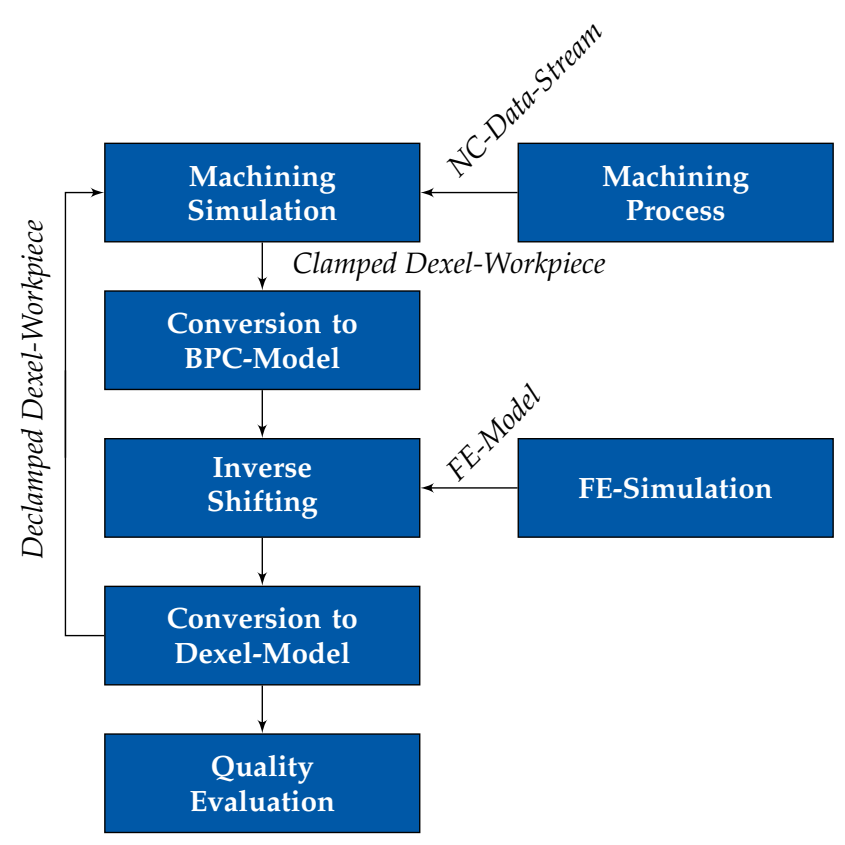

Fig. 2: Simulation Model
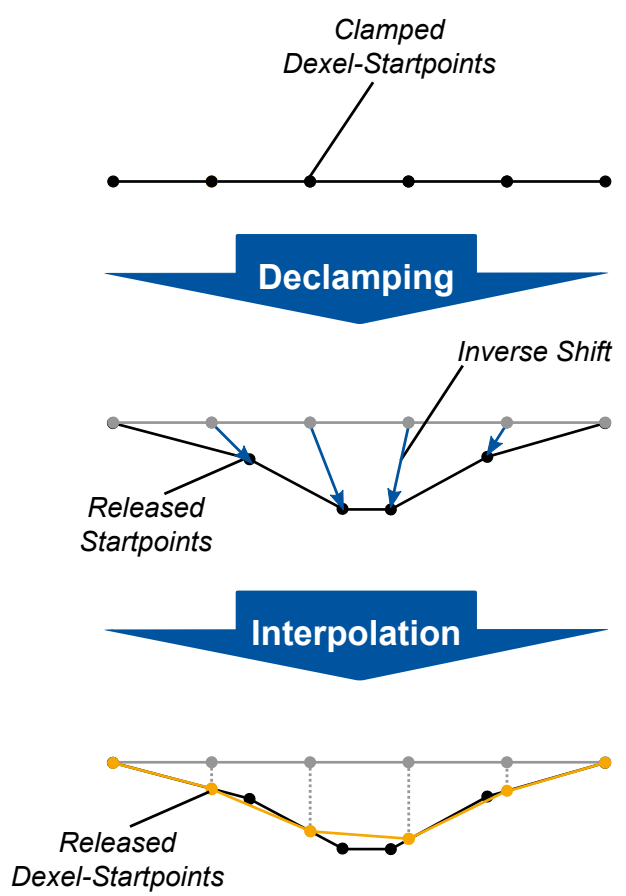

Fig. 3: Modeling Clamping Deflection in Dexel-Based Material Removal Simulations

\section{Experimental Validation}

To validate the approach, two different specimen workpieces were machined. Here, attention was paid to the fact that the workpiece distortion has a relevant influence on the workpiece quality. On the first part the clamping deformation was validated based on the flatness of the part. For the second part, the roundness was used. Both parts were manufactured from a (100 $\mathrm{mm} \times 100 \mathrm{~mm} \times 40 \mathrm{~mm}$ ) C45 steel block, as seen in Fig. 4 , and with a clamping force of 20 and $40 \mathrm{kN}$. Production was done on a DMG Mori DMU65 Monoblock, a 5-axis machining centre. In order to reduce thermal effects in the cutting zone and to keep the influence of the process force as low as possible, all processes were executed with cooling lubricant and a finishing process with low depth of cut. In addition, to parameterise the material removal simulation, the machine was measured before the first and after the last machining operation to determine the axis alignment errors using a double-ball bar (DBB), as these errors are particularly relevant for roundness [31]. A Zeiss Contura coordinate measuring machine (CMM) was used to measure the parts in the declamped state. It was shown that the simulation could be significantly improved with the help of the developed method. 


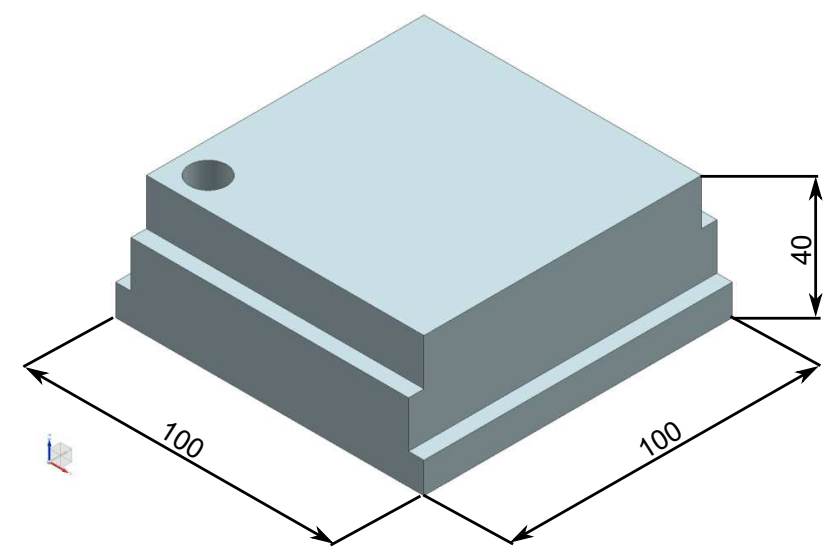

Fig. 4: Raw Part

\subsection{Flatness Error}

To validate the effect on flatness, the blanks were machined to a height of $20 \mathrm{~mm}$. The parts no. 1-6 were manufactured with a clamping force of $20 \mathrm{kN}$ and the parts no. 7-12 with a clamping force of $40 \mathrm{kN}$.

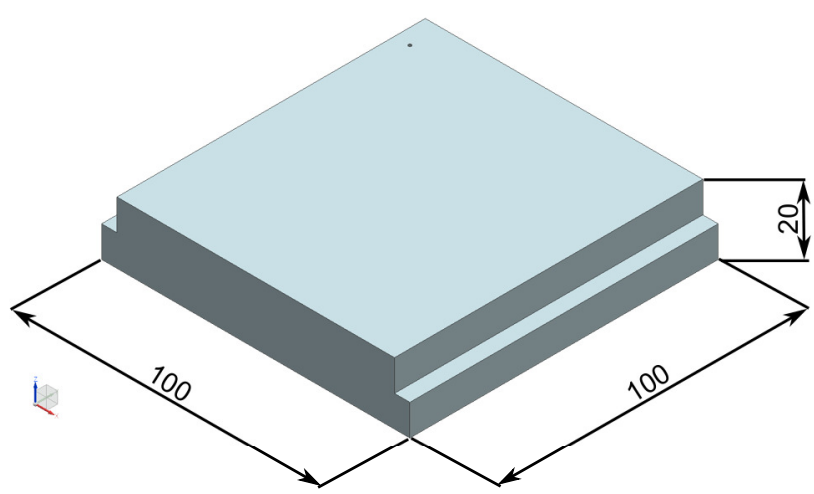

Fig. 5: Flatness Part

For validation, similar to [32], the point clouds from the material removal simulation and the CMM measurement are compared using a point cloud registration and flatness deviation. First, the point clouds are mapped using the 3D Normal Distribution Transform (3D-NDT) algorithm [33]. This is particularly suitable for point clouds with different resolutions and is robust against outliers $[33,34]$. The first occurs due to the fact that the dexel density of the simulation is usually significantly higher than the resolution of the measurement using CMM. After the point clouds are mapped to each other, the flatness and the resulting deviations in the Z-direction are determined for the congruent area.
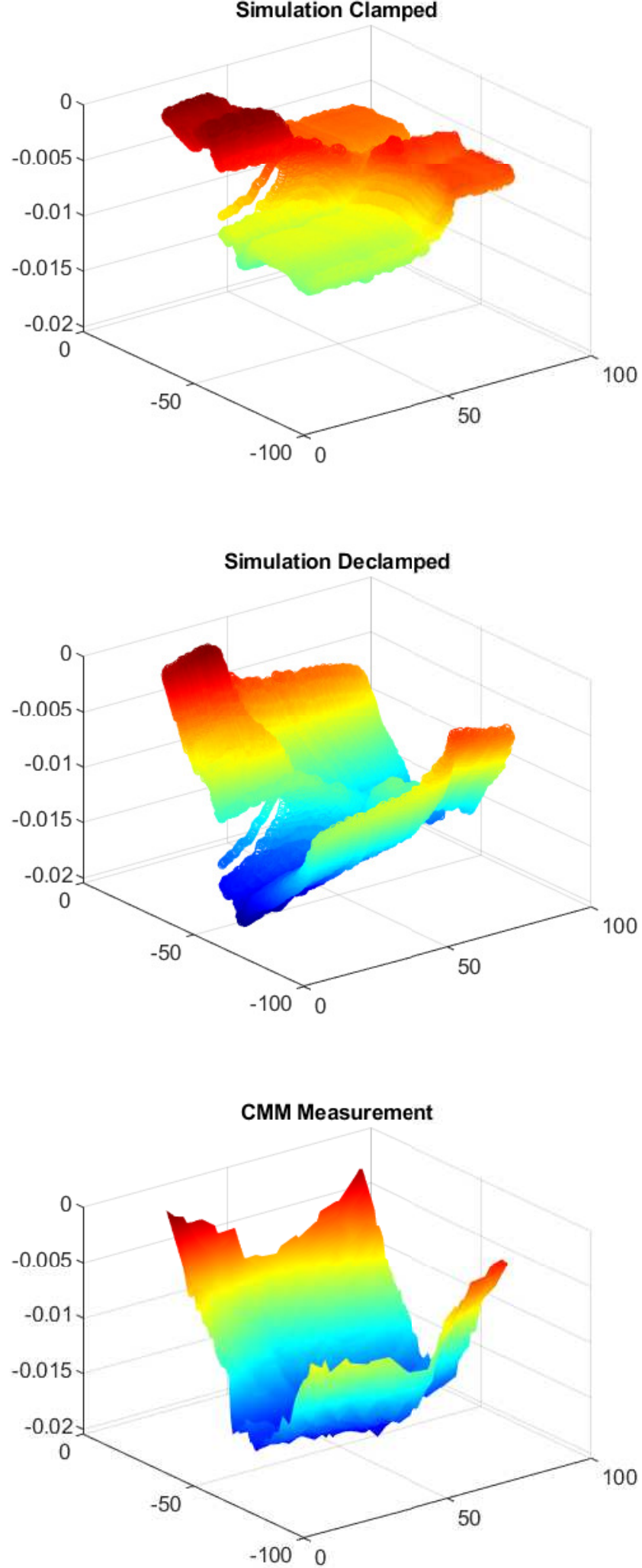

Fig. 6: Comparsion Flatness 


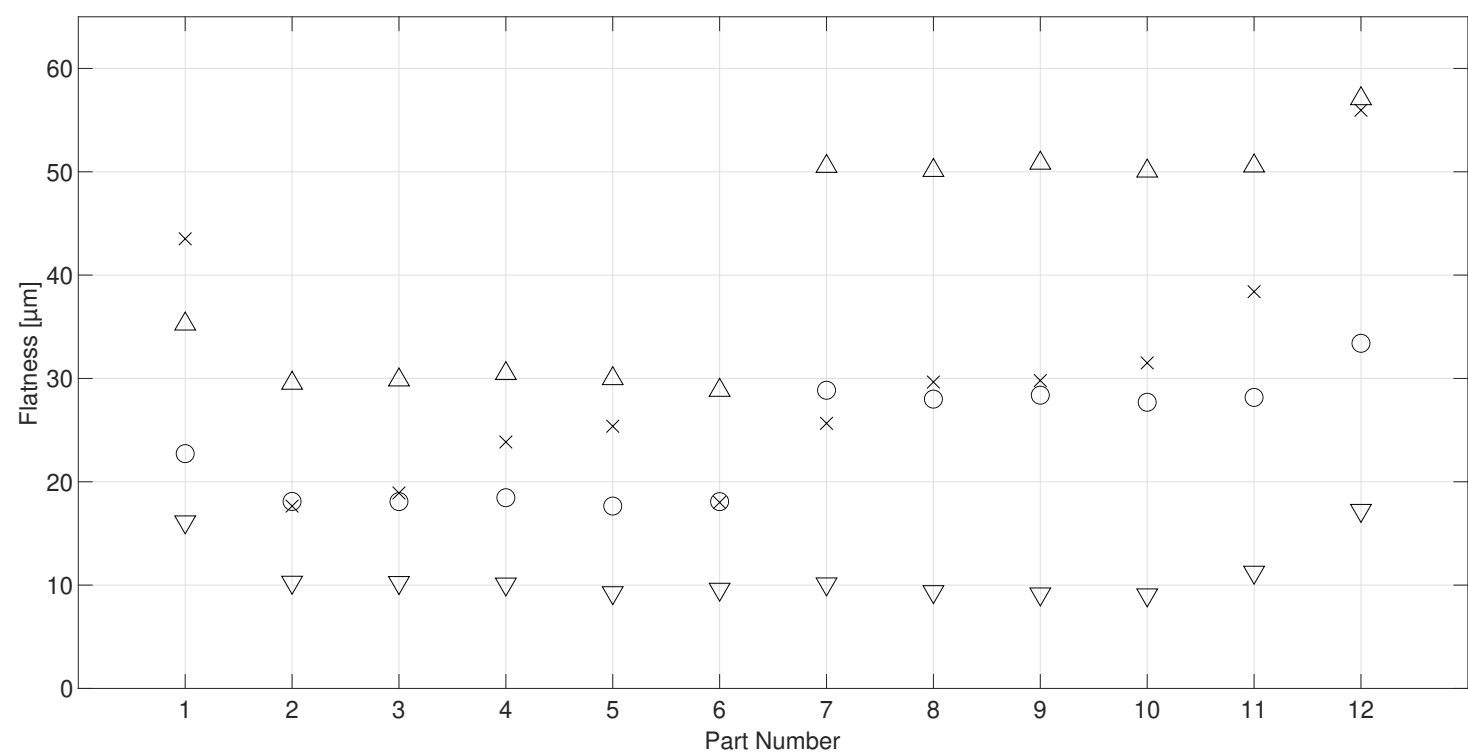

$\times \quad$ CMM - Measurement $\quad \bigcirc \quad$ Simulation with Clamping Deflection - relevant area $\triangle$ Simulation with Clamping Deflection - full surface $\quad \nabla \quad$ Simulation without Clamping Deflection

Fig. 7: Resulting Flatness
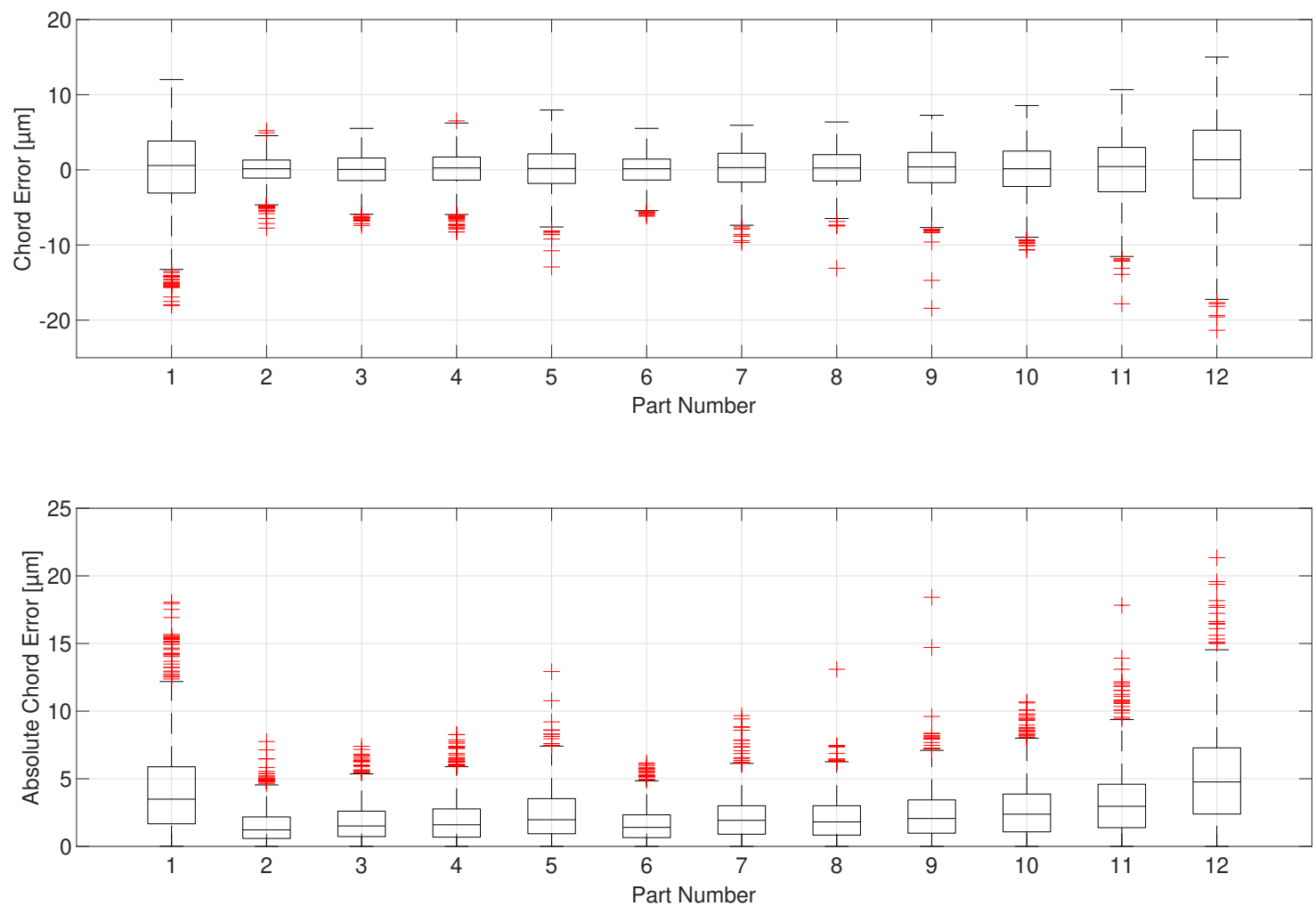

Fig. 8: Resulting Chord Error with Deflection - Flatness Evaluation 

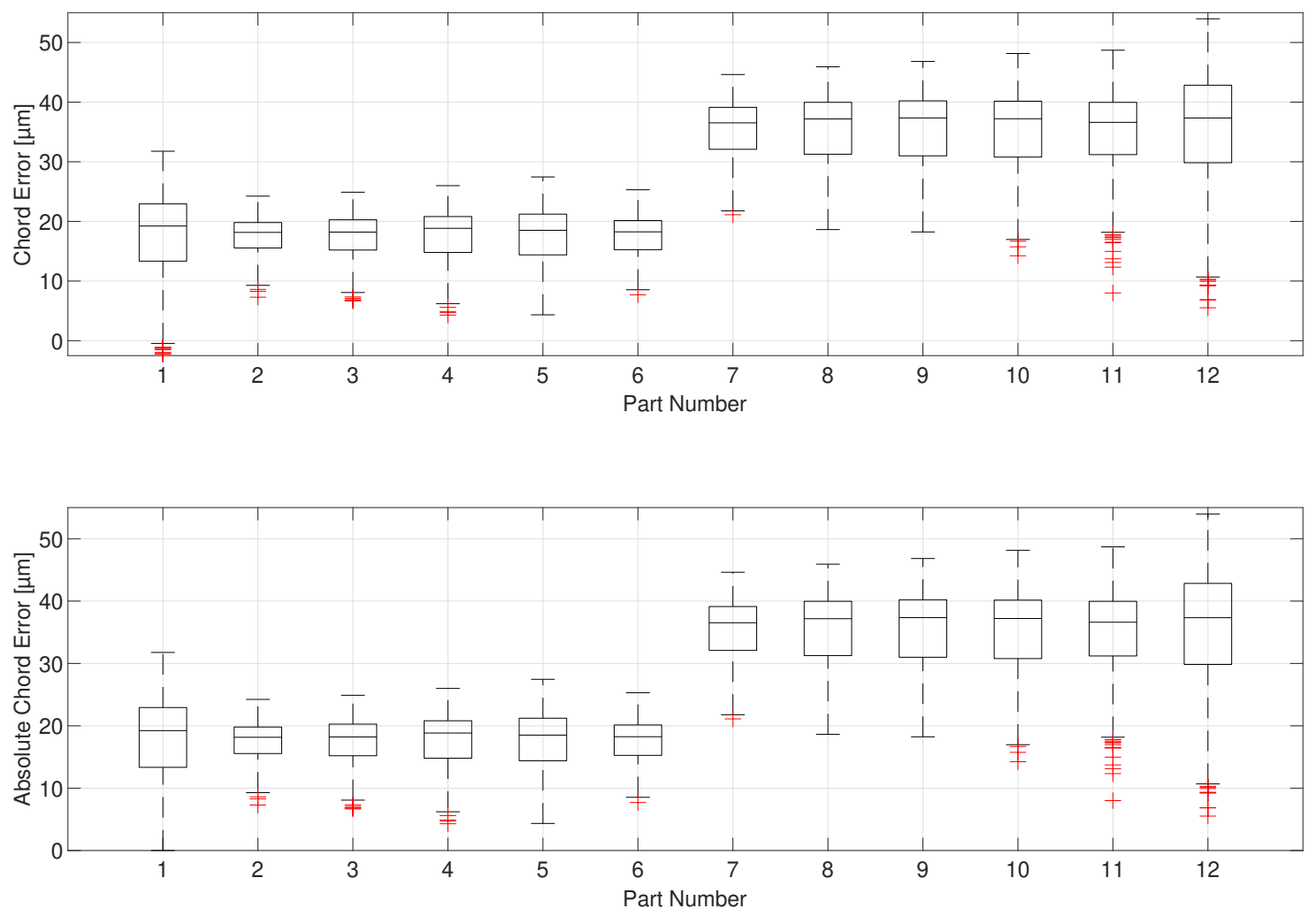

Fig. 9: Resulting Chord Error without Deflection - Flatness Evaluation

Fig. 7 shows the results of the consequent flatnesses of the individual parts for boh the CMM measurements and the simulation. For the simulation results, in addition to the flatness of the declamped part in the congruent area, the flatness of the entire surface, neglecting the centring hole, and the flatness in the congruent area of the part without taking the clamping conditions into account are also shown.

Since the flatness is only represented by the difference between the upper and lower deviation from the reference plane and does not give any conclusions about the form similarity of both surfaces, this approach is only sufficient for validation. One possibility to compare both surfaces is the resulting chord error. Since outliers, as seen in Fig. 7 at part no. 1 and 12, can also strongly influence the evaluation here, boxplots of the resulting chord error between CMM measurement and simulation are generated for the individual parts. Due the convexity in the present application is much lower compared to the remaining part dimensions, it is assumed via small-angle feeding that the resulting chord error is equal to the difference of the Z-values.
Comparing the resulting cord errors between a considered (Fig. 8) and a neglected clamping situation (Fig. 9), it becomes apparent that the prediction quality of the simulation is improved significantly. Therefore, the interquartile range and the whiskers show that the deviations of the (absolute) chord error are significantly reduced.

\subsection{Roundness Error}

While mainly the displacements in Z-direction influence the workpiece quality for flatnesses, the displacements in the X- and Y-direction are relevant for the roundness. Here, in addition to the displacement of the circle edge, there is also a displacement of the centre point. To validate the approach, the blank was facemilled to a height of $20 \mathrm{~mm}$ first, as in the case of the flatness validation. Then, a hole with a diameter of 60 $\mathrm{mm}$ was milled in the centre of the part using a $\varnothing 16$ $\mathrm{mm}$ end mill.Twelve parts were produced with a clamping force of $20 \mathrm{kN}$ (parts no. 1-6) and $40 \mathrm{kN}$ (parts no. 7-12), respectively. 


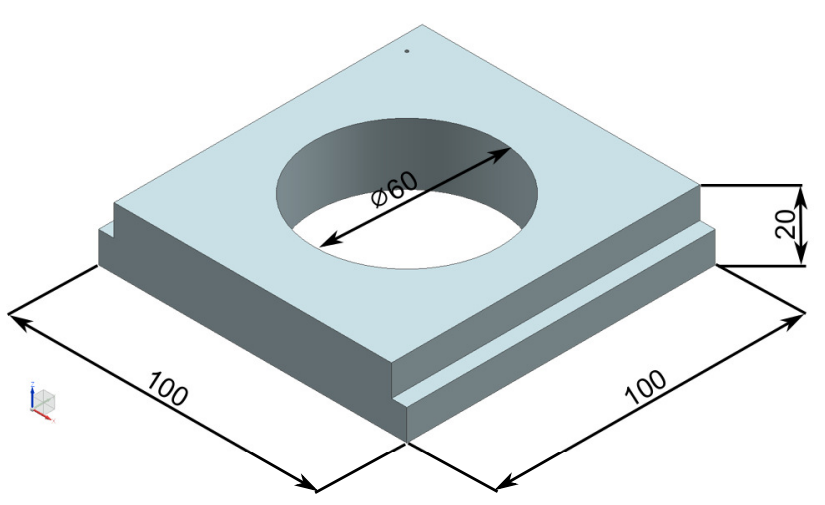

Fig. 10: Roundness Part

After production, the roundness of the parts was measured on the CMM at three different heights. The three measurements are aggregated to a total point cloud. Afterwards, this is aligned to the relaxed BPC model using the 3D-NDT algorithm so that the relevant points of the simulation can be identified. For each measurement, a separate point cloud from the simulation is selected for both the clamped and declamped states. With the help of a circle fitting according to [35], the centres of the respective circles are determined so that the resulting radius can be derived over the angle. By comparing the deviations between the radii of the measured and the simulated parts, here the interquartile range and the whiskers also show that the deviations are significantly reduced. Fig. 11 and 12 illustrate this for all measurements.

\section{Conclusion}

In the machining process, various effects can compromise components that influence the quality of the workpiece. Especially parts with a low stiffness in the final state are deformed by clamping forces. In this article, a method was presented that makes it possible to reproduce this effect in dexel-based material removal simulations. The presented approach has the advantage that it works independently of the raw part and the virtual workpiece can be used for successive process simulations. In addition, three-dimensional deformations can be modelled. Furthermore, it offers the possibility of a more precise error breakdown in process monitoring with the help of machine-internal data. A disadvantage of this approach is that only the start and end points can be changed while new/old start and end points cannot be added/removed. Nevertheless, it was shown that the presented approach can improve dexel-based material removal simulations for parts with a relevant clamping force deflection. The approach was validated on the basis of two specimen workpieces, so that the effect could be reproduced in all three directions.

Acknowledgements This paper was written in the context of the research project "Quality Predictive CAM Simulation for Machining (QUAPS)". The IGF project $19828 \mathrm{~N}$ of the Forschungsvereinigung Programmiersprachen für Fertigungseinrichtungen e. V. (FVP) was funded via the German Federation of Industrial Research Associations (AiF) as part of the program to promote joint industrial research (IGF) by the Federal Ministry of Economics and Energy on the basis of a resolution of the German Bundestag.

\section{Declarations}

Ethical Approval Neither the entire paper nor any part of its content has been published or has been accepted elsewhere. It is not being submittedto any other journal.

Consent to participate The authors consent to participate in this work.

Consent to publication The authors consent to publish this paper on "The International Journal of Advanced Manufacturing Technology".

Author contribution The persons making contributions on this work have been listed in author information

Funding Open Access funding enabled and organized by Projekt DEAL.

Conflict of interest The authors declare that they have no conflict of interest.

Availability of data and material The authors confirm that the data supporting the findings of this study are available within the article.

\section{References}

1. A.Y.C. Nee, K. Whybrew, A. Senthil kumar, Advanced fixture design for FMS. Advanced manufacturing series (Springer, London, 1995)

2. Y. Altintas, P. Kersting, D. Biermann, E. Budak, B. Denkena, I. Lazoglu, CIRP Annals 63(2), 585 (2014). DOI 10.1016/j.cirp.2014.05.007

3. Y. Altintas, S. Tulsyan, CIRP Annals 64(1), 361 (2015). DOI 10.1016/j.cirp.2015.04.100

4. C. Brecher, Realisierung effizienter Zerspanprozesse: Ergebnisbericht des BMBF Verbundprojekts ReffiZ. Produktentwicklung (Shaker Verl., Aachen, 2015)

5. W. Hunt, H. Voelcker, An exploratory study of automatic verification of programs for numerically controlled machine tools. Technical Report, University of Rochester, New York (01.1982) 

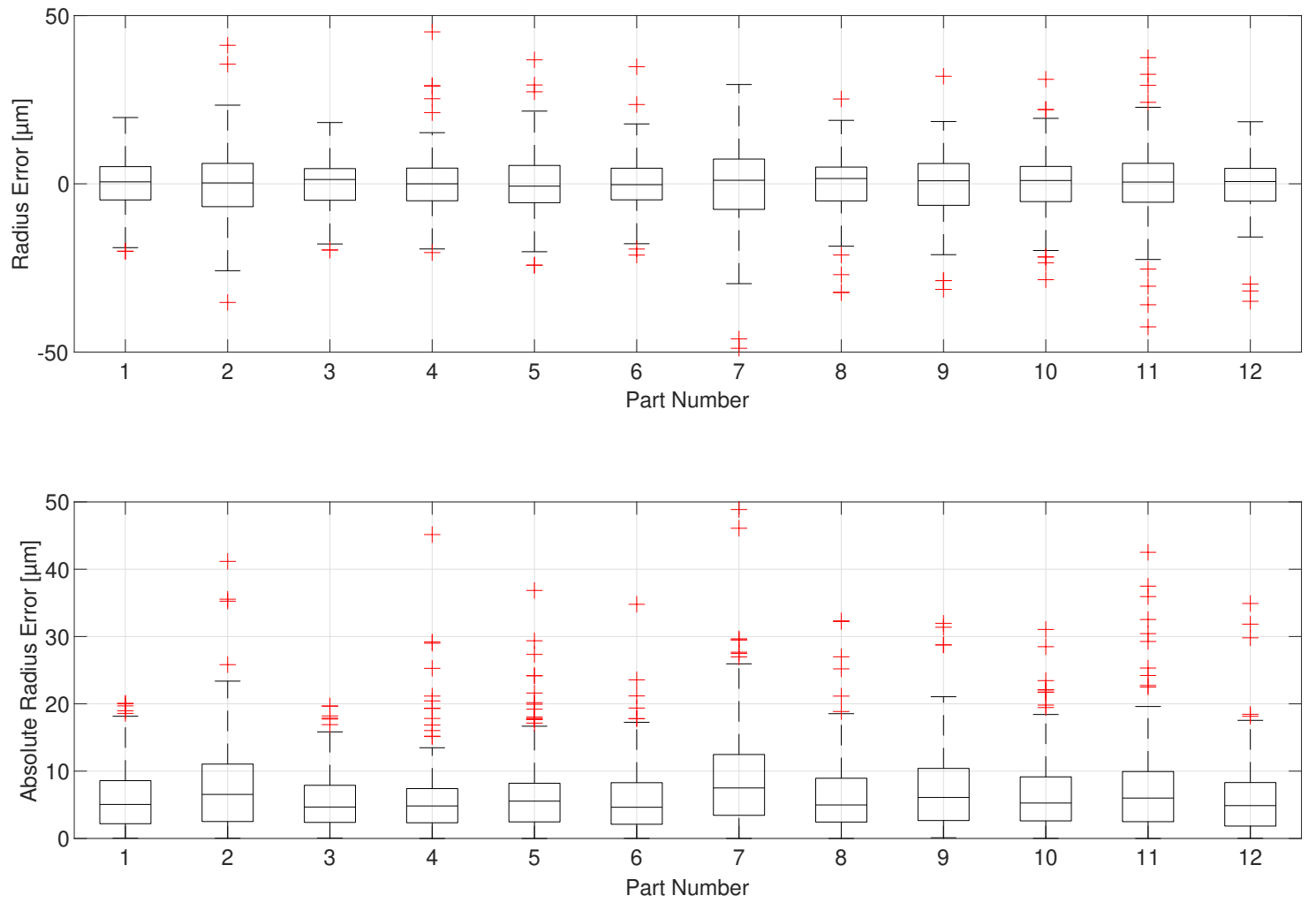

Fig. 11: Resulting Radius Error with Deflection - Roundness Evaluation
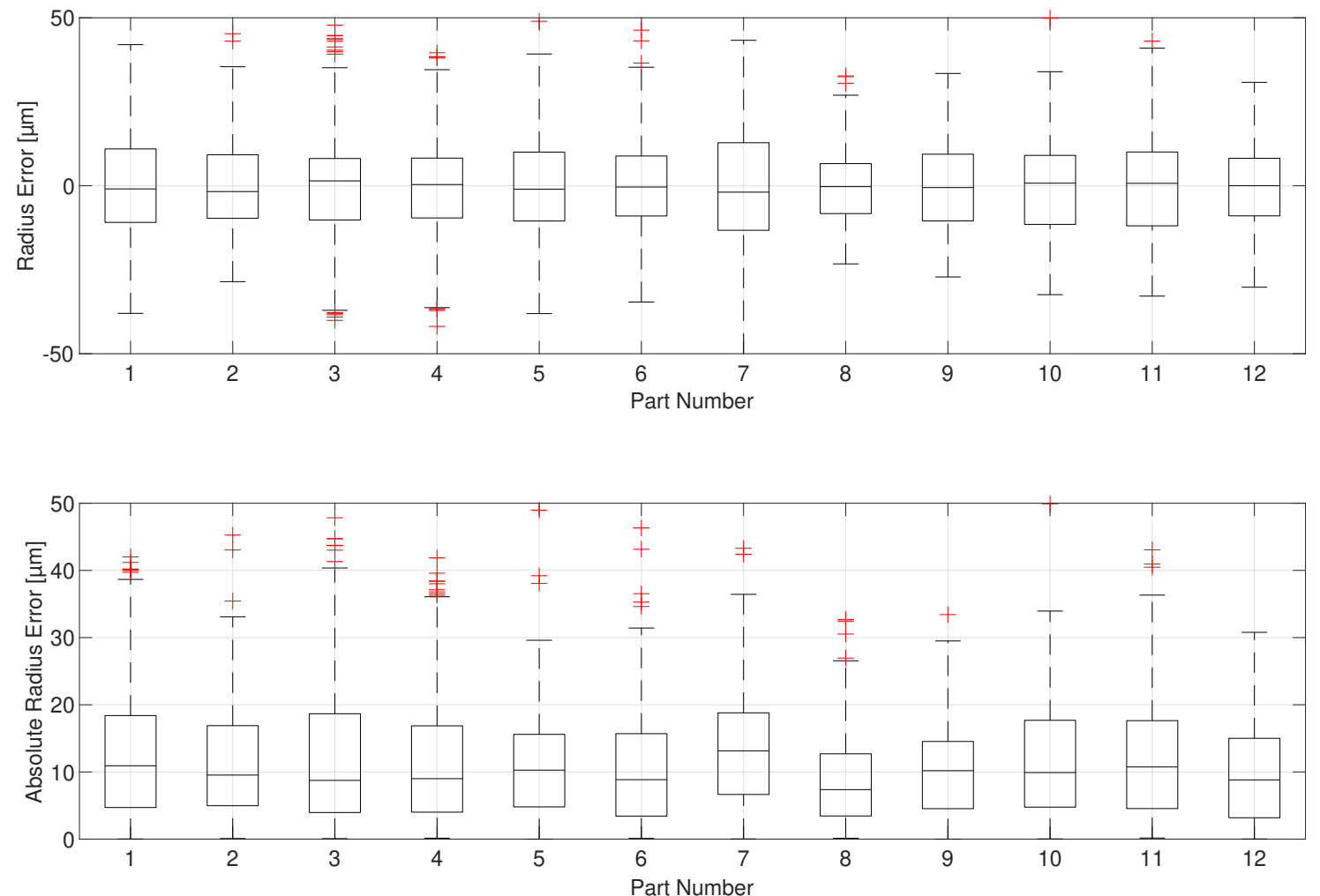

Fig. 12: Resulting Radius Error without Deflection - Roundness Evaluation 
6. B. Denkena, H.K. Tönshoff, Spanen: Grundlagen, 3rd edn. VDI-Buch (Springer Fachmedien, Wiesbaden, 2011). DOI 10.1007/978-3-642-19772-7

7. C. Brecher, F. Wellmann, A. Epple, Procedia Manufacturing 11, 1519 (2017). DOI 10.1016/j.promfg.2017.07.284

8. B. Denkena, M.A. Dittrich, F. Uhlich, Procedia CIRP 57, 487 (2016). DOI 10.1016/j.procir.2016.11.084

9. Y. Altintas, D. Aslan, CIRP Annals 66(1), 349 (2017). DOI 10.1016/j.cirp.2017.04.047

10. M. Königs, C. Brecher, Procedia Manufacturing 26, 1087 (2018). DOI 10.1016/j.promfg.2018.07.145

11. Y. Altintas, J. Yang, Z.M. Kilic, CIRP Annals 68(1), 377 (2019). DOI 10.1016/j.cirp.2019.04.019

12. E. Ungemach, T. Surmann, A. Zabel, Advanced Materials Research 43, 89 (2008). DOI 10.4028/www.scientific.net/AMR.43.89

13. B. Denkena, A. Schmidt, J. Henjes, D. Niederwestberg, C. Niebuhr, Procedia CIRP 8, 69 (2013). DOI 10.1016/j.procir.2013.06.067

14. M. Witt, M. Schumann, P. Klimant, The International Journal of Advanced Manufacturing Technology 105(5-6), 2321 (2019). DOI 10.1007/s00170-019-04418-2

15. A. Agarwal, K.A. Desai, Procedia CIRP 93, 1411 (2020). DOI 10.1016/j.procir.2020.04.101

16. S.P. Siebenaler, S.N. Melkote, International Journal of Machine Tools and Manufacture 46(1), 51 (2006). DOI 10.1016/j.ijmachtools.2005.04.007

17. B.L. Tai, D.A. Stephenson, A.J. Shih, International Journal of Machine Tools and Manufacture 51(6), 483 (2011). DOI 10.1016/j.ijmachtools.2011.02.006

18. G. Qin, W. Zhang, Z. Wu, M. Wan, Journal of Manufacturing Science and Engineering 129(4), 789 (2007). DOI $10.1115 / 1.2336260$

19. P. Chavan, C. Brecher, M. Fey, M. Loba, in Dynamic Substructures, Volume 4, ed. by A. Linderholt, M.S. Allen, R.L. Mayes, D. Rixen, Conference Proceedings of the Society for Experimental Mechanics Series (Springer International Publishing and Imprint: Springer, Cham, 2020), pp. 47-56. DOI 10.1007/978-3-030-12184-6_5

20. W. Chen, L. Ni, J. Xue, The International Journal of Advanced Manufacturing Technology 38(9-10), 860 (2008). DOI 10.1007/s00170-007-1153-2

21. B. Li, S.N. Melkote, The International Journal of Advanced Manufacturing Technology 17(2), 104 (2001). DOI $10.1007 / \mathrm{s} 001700170198$

22. Y. Huang, T. Hoshi, Precision Engineering 24(4), 364 (2000). DOI 10.1016/S0141-6359(00)00047-7

23. M. DOBRZYNSKI, D. CHUCHALA, K.A. ORLOWSKI, Journal of Machine Engineering Vol.18(No.1), 81 (2018). DOI 10.5604/01.3001.0010.8825

24. S. Knape, M. Königs, A. Epple, C. Brecher, in Advances in Production Research, ed. by R. Schmitt, G. Schuh (Springer International Publishing, Cham, 2019), pp. 72-80. DOI 10.1007/978-3-030-03451-1_8

25. C. Brecher, M. Fey, M. Loba, ZWF Zeitschrift für wirtschaftlichen Fabrikbetrieb 114(11), 753 (2019). DOI 10.3139/104.112181

26. Y. Yamada, Y. Kakinuma, The International Journal of Advanced Manufacturing Technology 87(9-12), 3337 (2016). DOI 10.1007/s00170-016-8710-5

27. Statistics for Thematic Cartography (2021). URL http:/ / www.gitta.info/Statistics/en/html/StandClass_learningObject2.html

28. G.F. JENKS, F.C. CASPALL, Annals of the Association of American Geographers 61(2), 217 (1971). DOI 10.1111/j.1467-8306.1971.tb00779.x

29. I. Amidror, Journal of Electronic Imaging 11(2), 157 (2002). DOI $10.1117 / 1.1455013$
30. DIN Deutsches Institut für Normung e. V. Geometrische Produktspezifikation (GPS) - Geometrische Tolerierung - Tolerierung von Form, Richtung, Ort und Lauf (ISO 1101:2017); Deutsche Fassung EN ISO 1101:2017 (2017)

31. C. Brecher, M. Weck, Werkzeugmaschinen Fertigungssysteme (Springer Berlin Heidelberg, Berlin, Heidelberg, 2017). DOI 10.1007/978-3-662-46567-7

32. H.S. Park, U.M. Tuladhar, International Journal of Automotive Technology 17(1), 119 (2016). DOI $10.1007 / \mathrm{s} 12239-016-0011-3$

33. M. Magnusson, The Three-Dimensional Normal-Distributions Transform: An Efficient Representation for Registration, Surface Analysis, and Loop Detection, Örebro Studies in Technology, vol. 36 (Örebro universitet, Örebro, 2009)

34. T. Stoyanov, M. Magnusson, A.J. Lilienthal, in IEEE International Conference on Robotics and Automation (ICRA), 2012 (IEEE, Piscataway, NJ, 2012), pp. 5196-5201. DOI 10.1109/ICRA.2012.6224717

35. V. Pratt, ACM SIGGRAPH computer graphics 21(4), 145 (1987) 
Figures
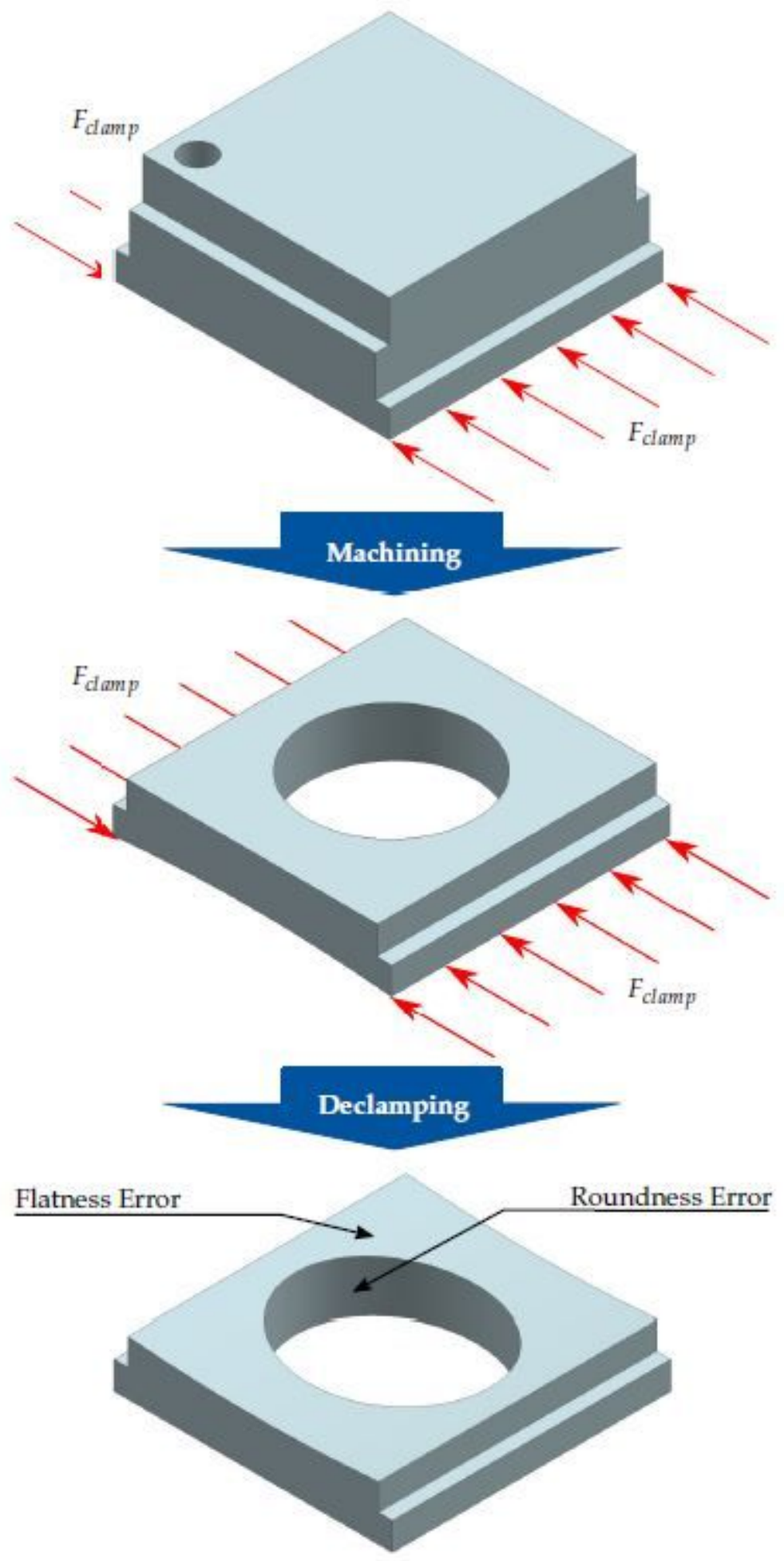

Figure 1

Clamping Deflection Errors 


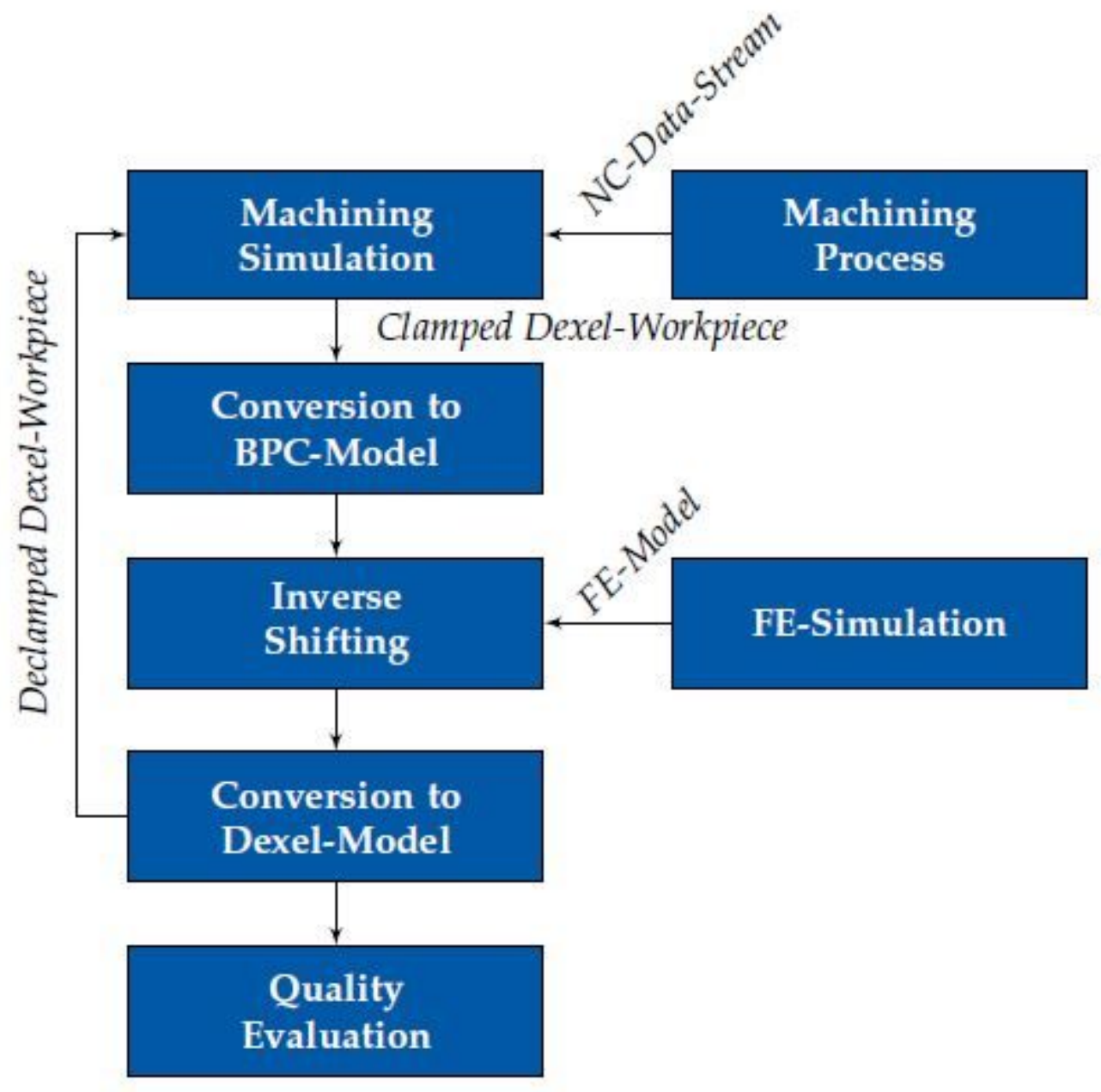

Figure 2

Simulation Model 

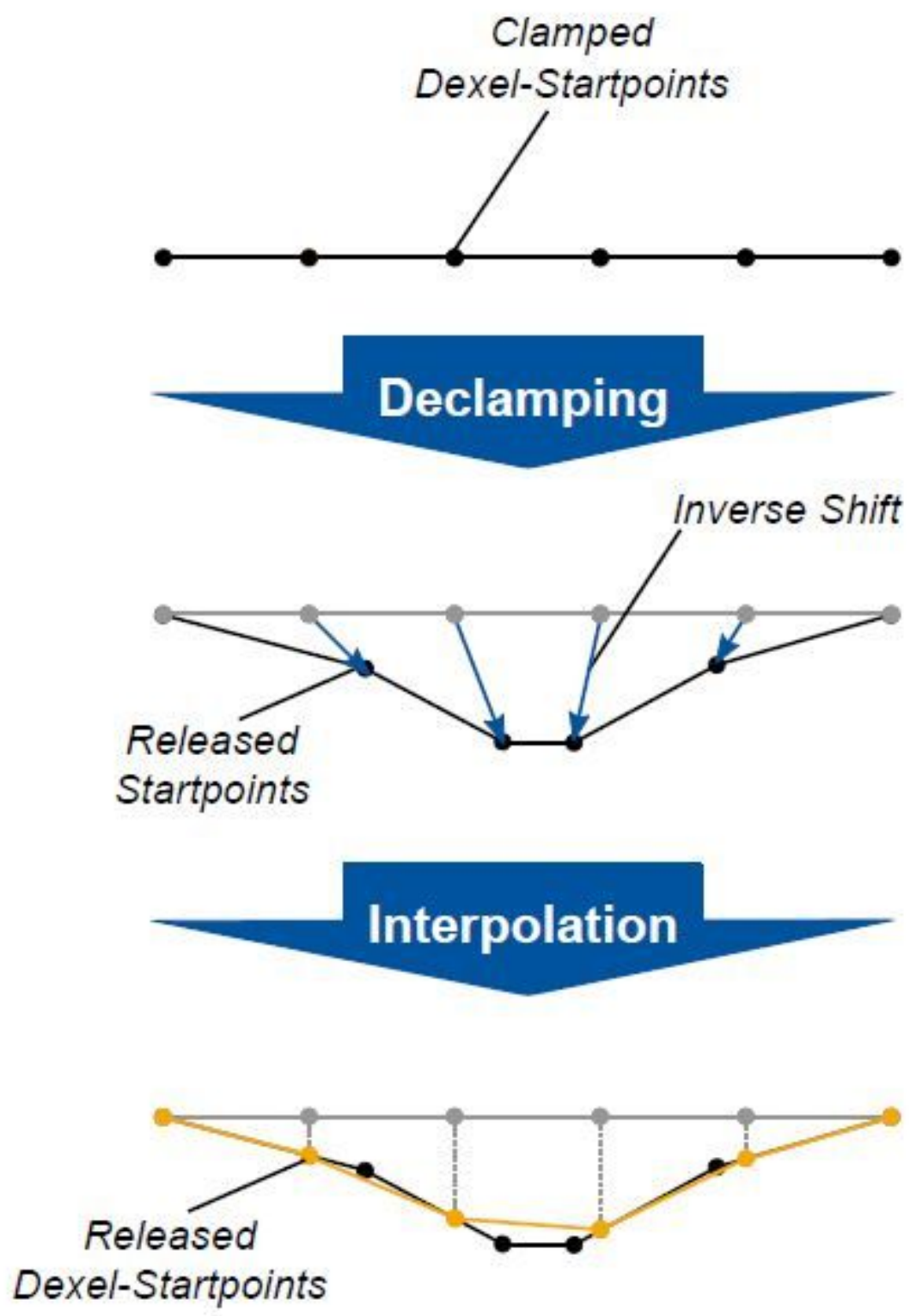

Figure 3

Modeling Clamping Deflection in Dexel-Based Material Removal Simulations 


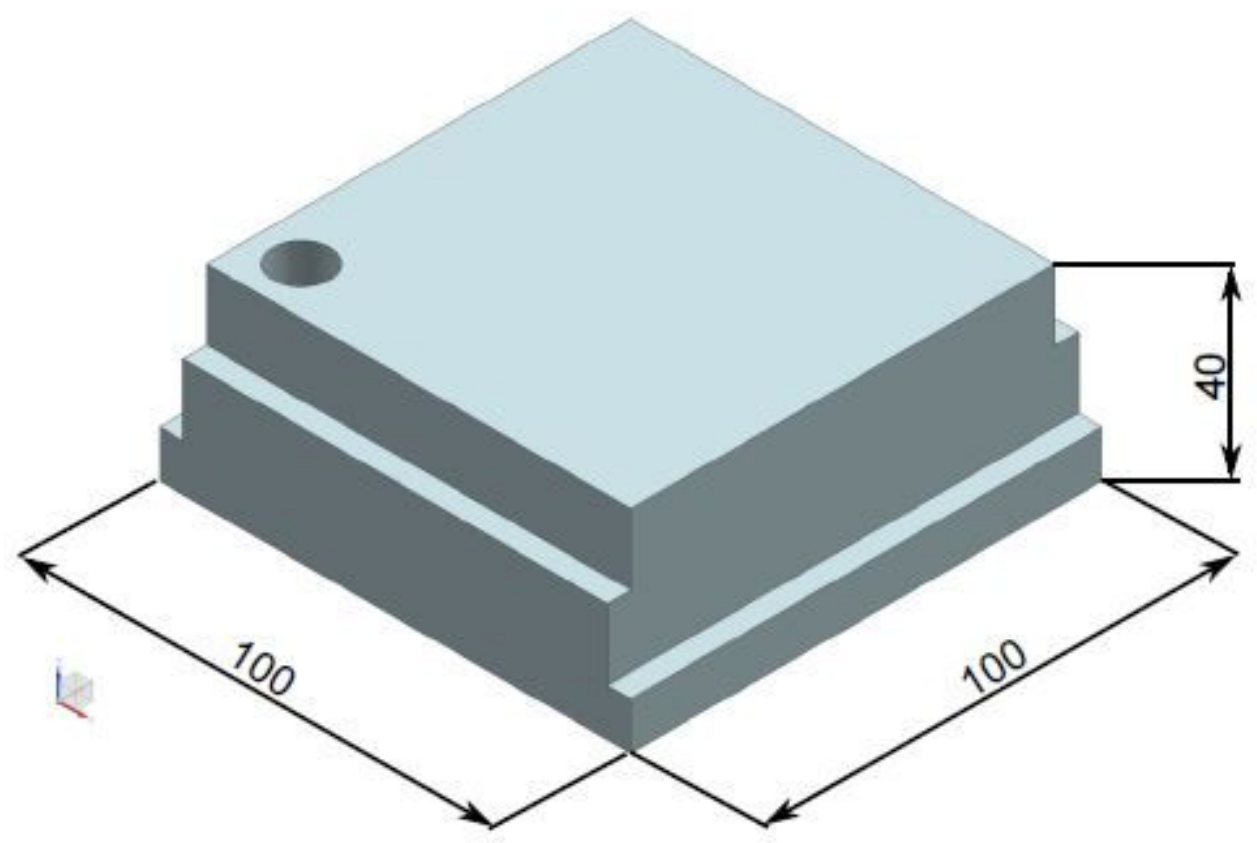

Figure 4

Raw Part

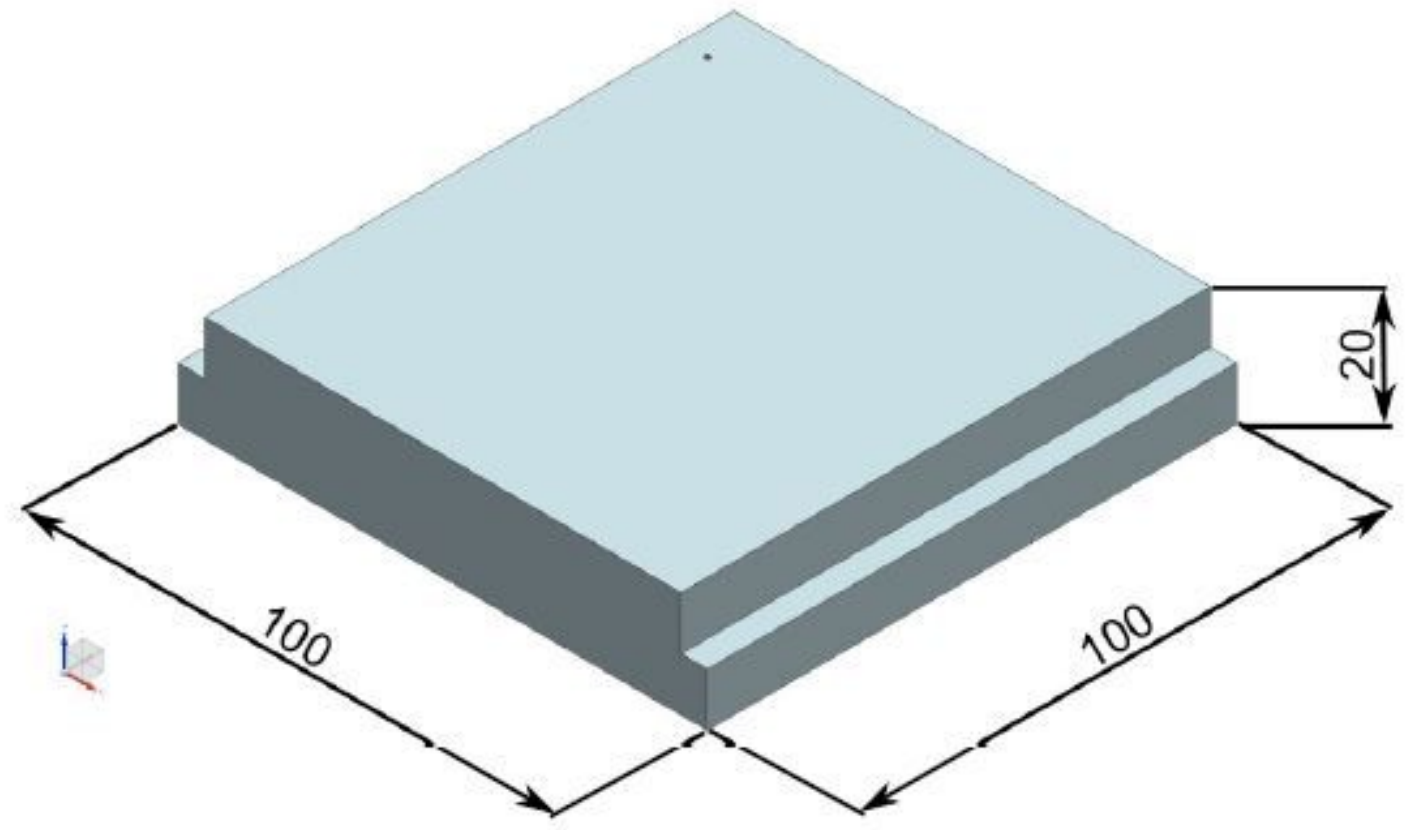

Figure 5

Flatness Part 

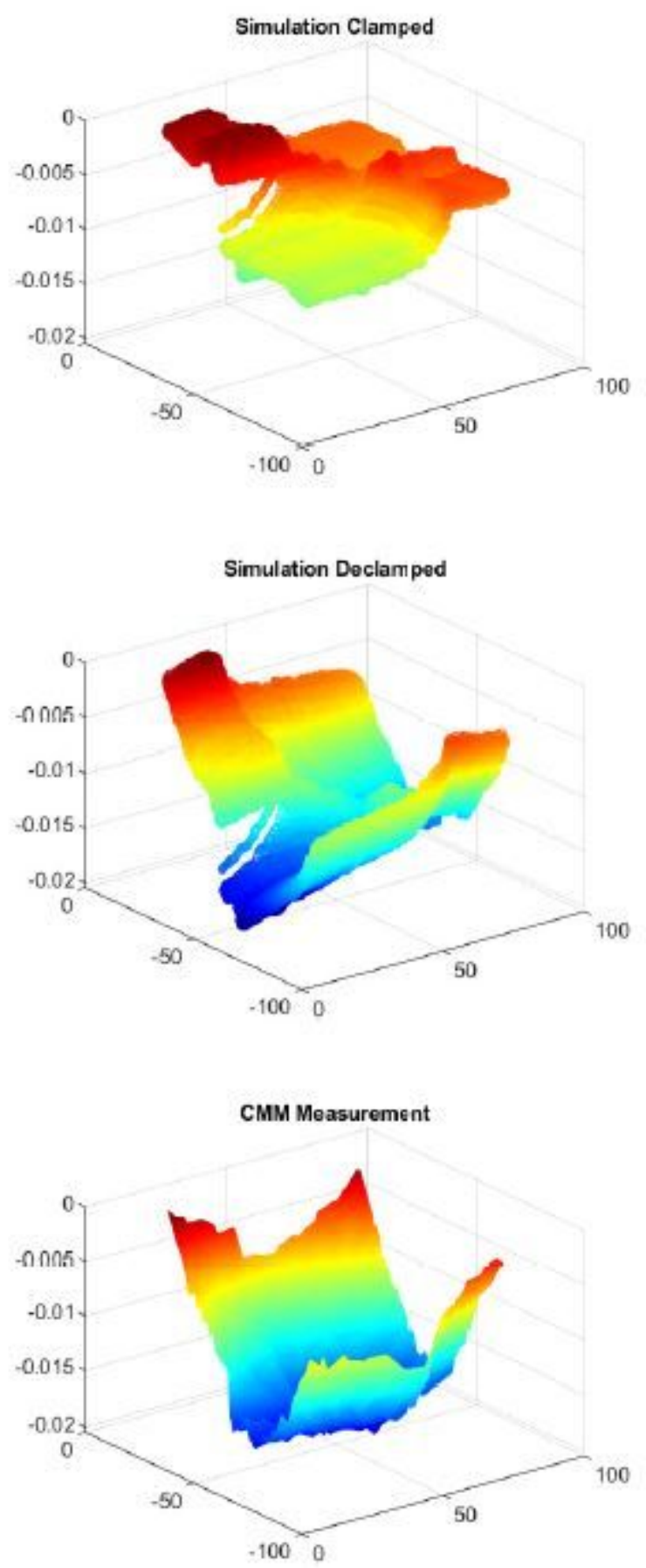

Figure 6

Comparsion Flatness 


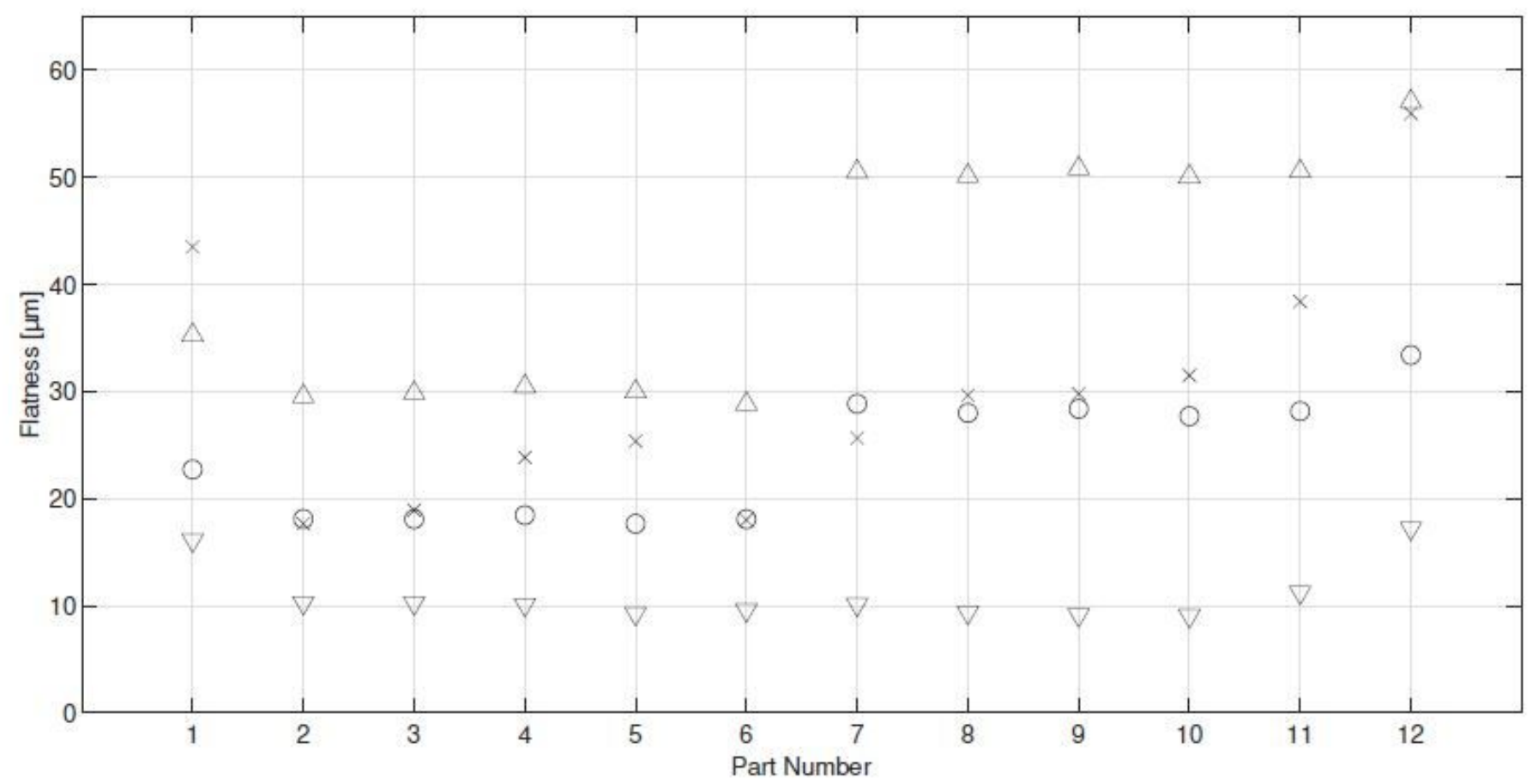

$\begin{array}{llll}\times & \text { CMM - Measurement } & 0 & \text { Simulation with Clamping Deflection - relevant area } \\ \Delta \quad \text { Simulation with Clamping Deflection - full surface } & \nabla & \text { Simulation without Clamping Deflection }\end{array}$

\section{Figure 7}

\section{Resulting Flatness}



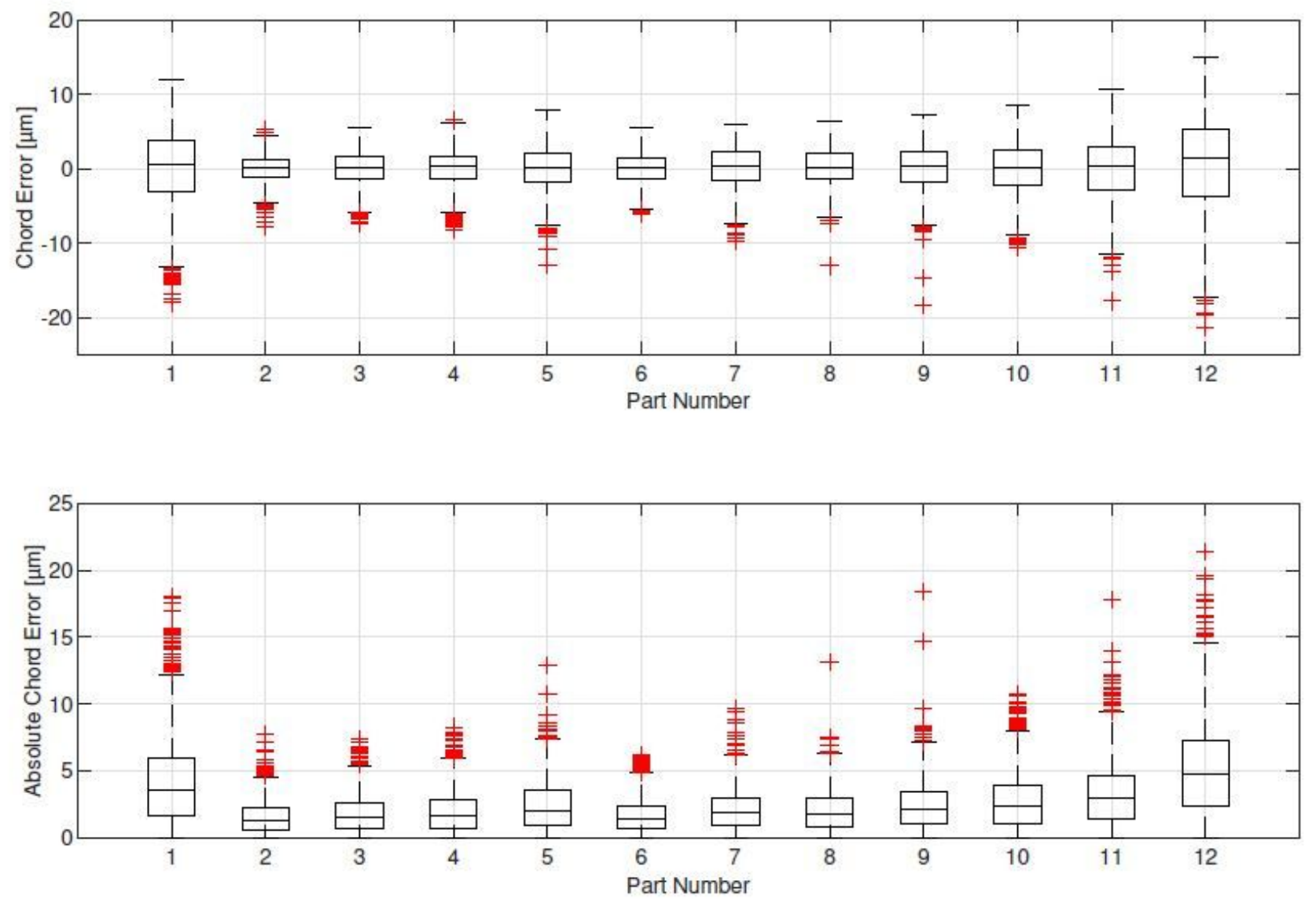

Figure 8

Resulting Chord Error with Deflection - Flatness Evaluation 

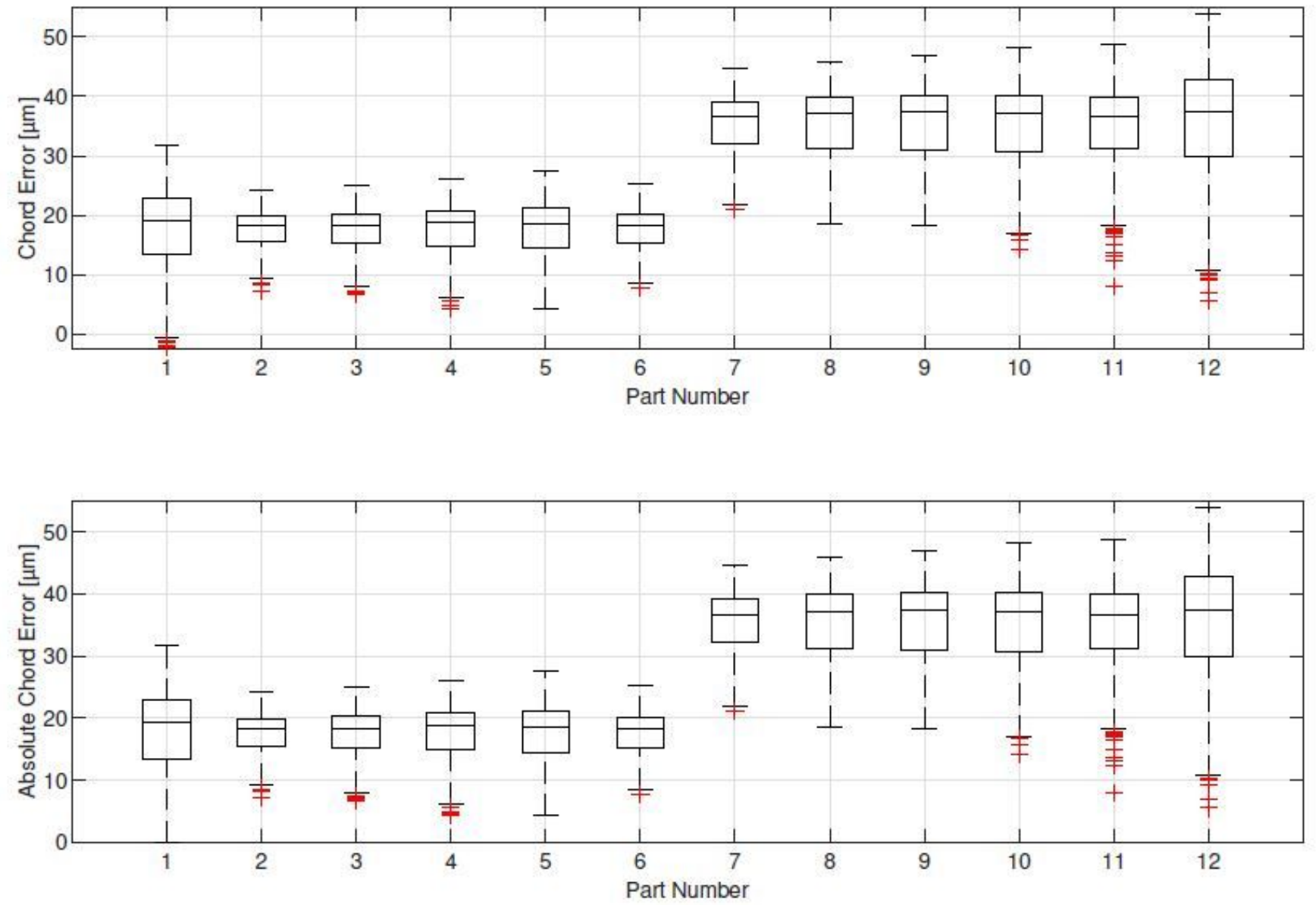

Figure 9

Resulting Chord Error without Deflection - Flatness Evaluation

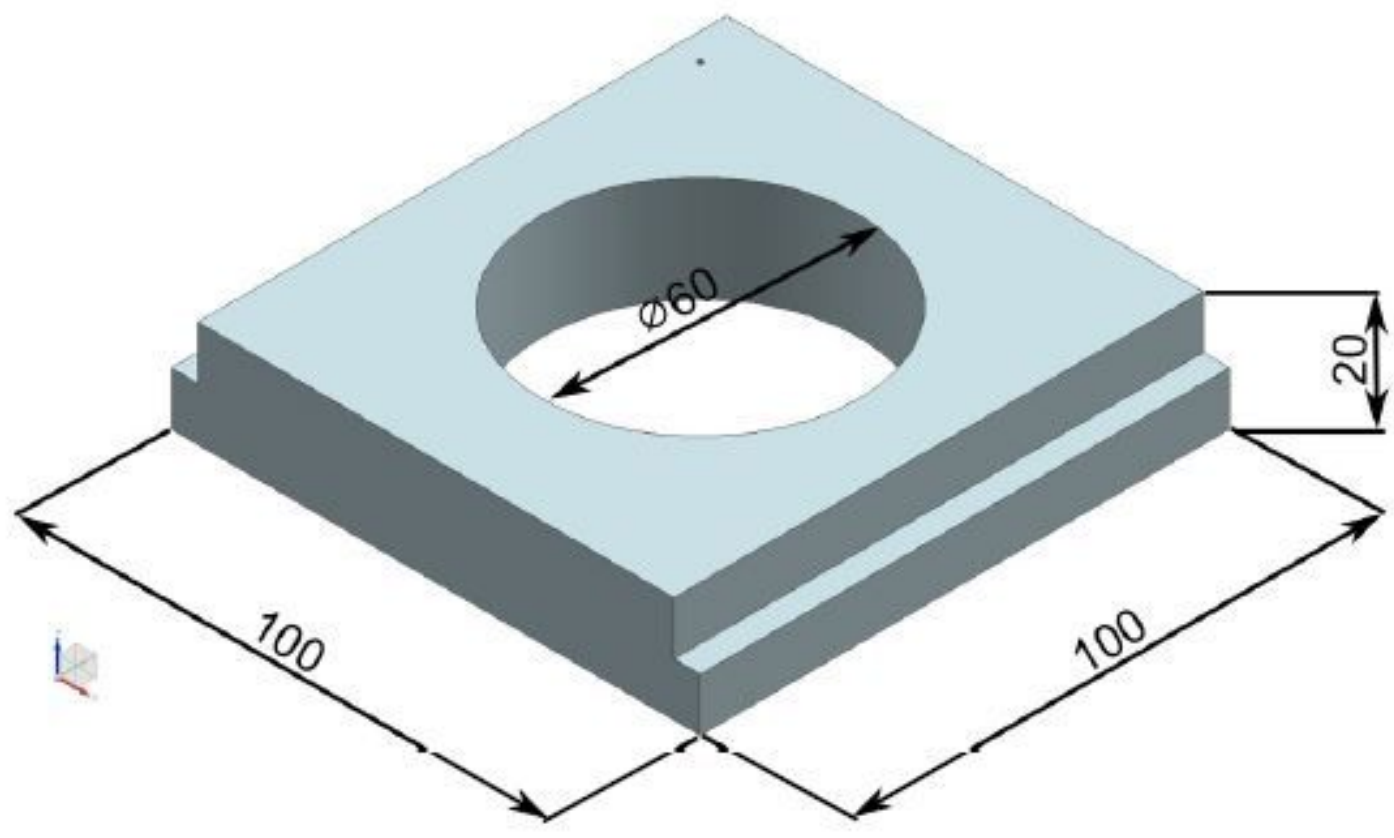


Figure 10

Roundness Part
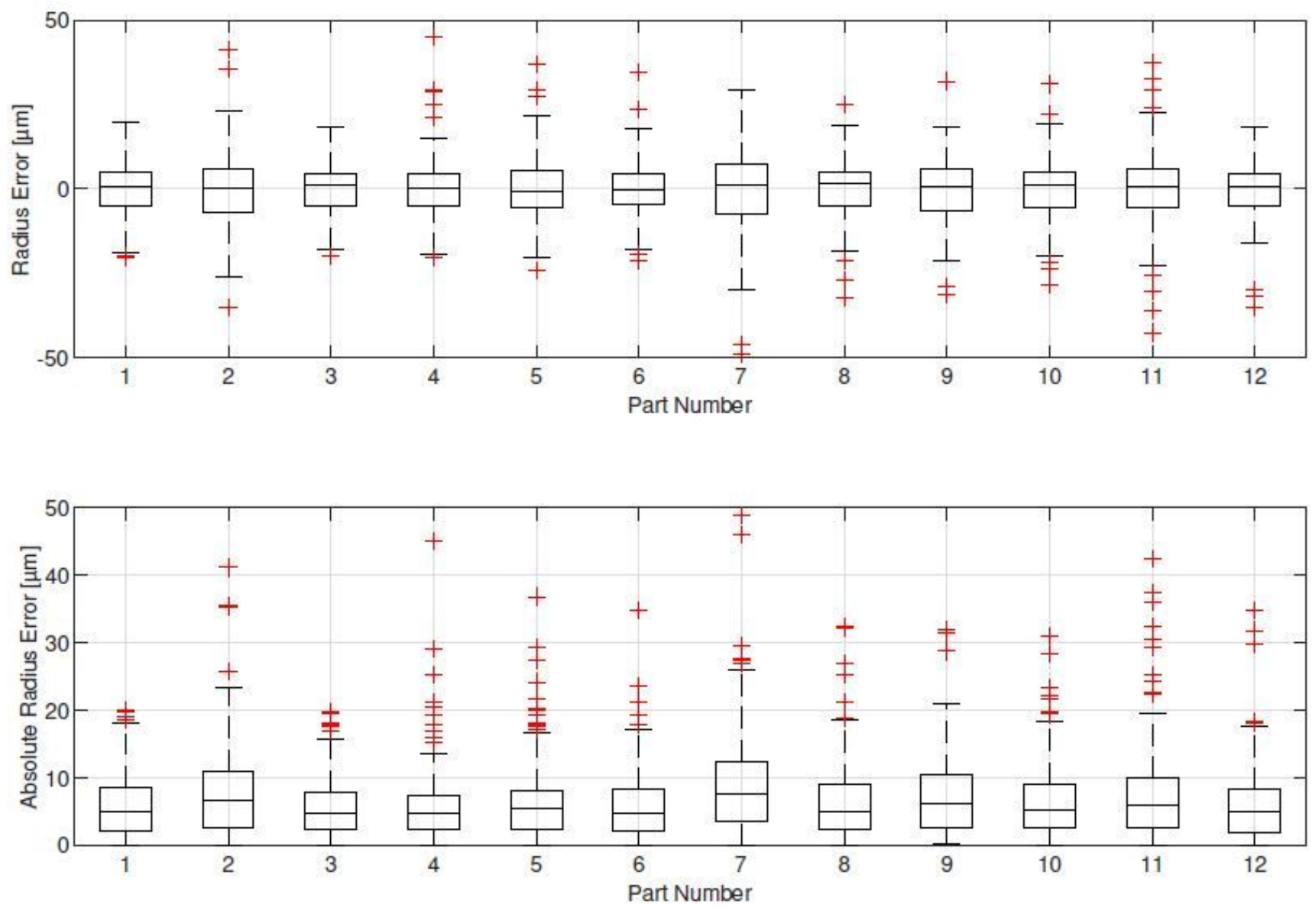

Figure 11

Resulting Radius Error with Deflection - Roundness Evaluation 

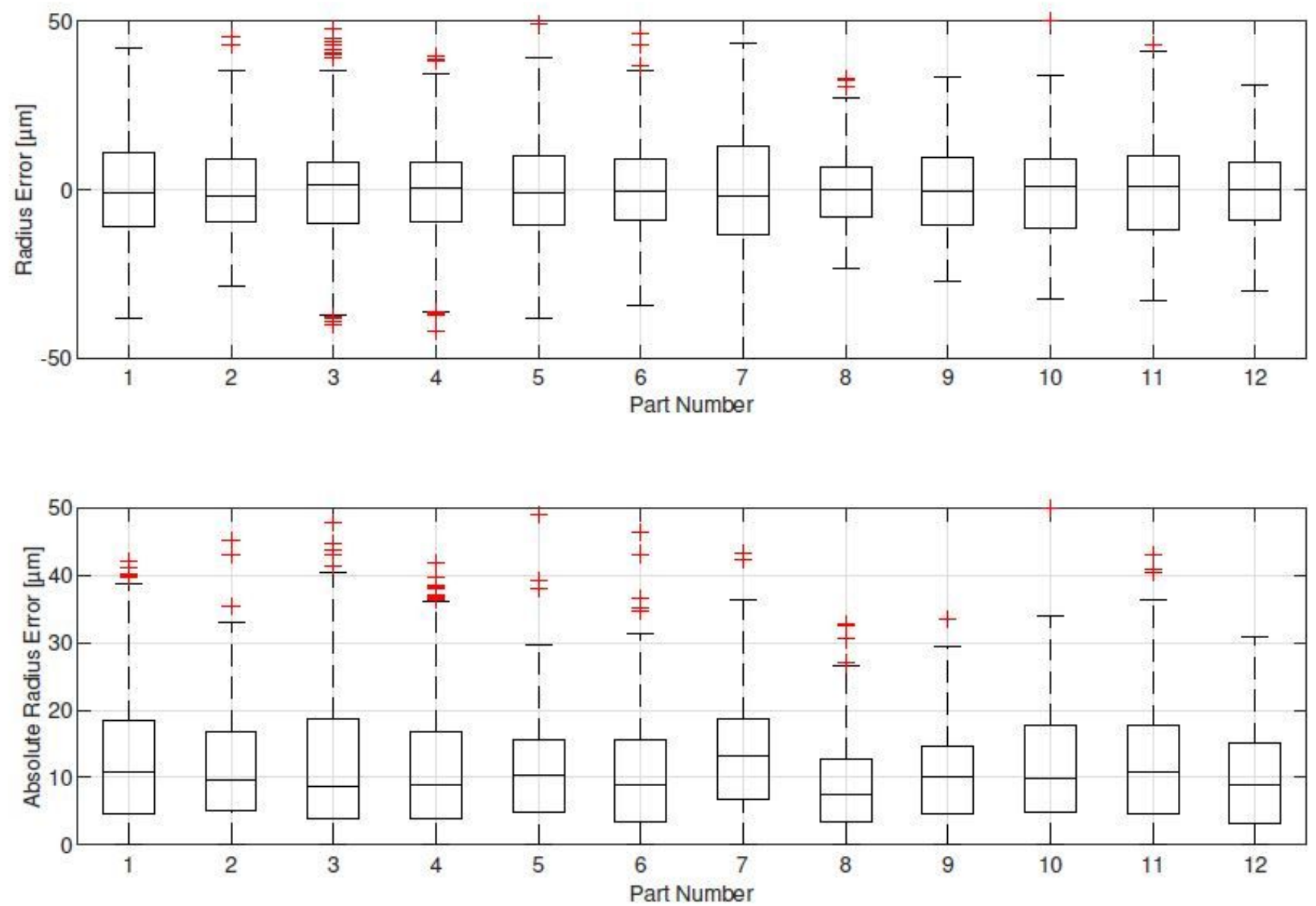

Figure 12

Resulting Radius Error without Deflection - Roundness Evaluation 